\title{
Using real-world data to estimate the changing trends in the prevalence and incidence of type 2 diabetes mellitus in Xiamen of China from 2014 to 2019
}

Weiwei He $e^{1,2,3+} \mathbb{D}$, Qiushi Xu ${ }^{4 \dagger}$, Lili Han ${ }^{5}$, Ting Wu' ${ }^{5}$ Xiulin Shi ${ }^{2,3,6}$, Lishan Ye ${ }^{4}$, Guanhua Yao ${ }^{7}$ and Xuejun $\mathrm{Li}^{2,3,6^{*}}$

\begin{abstract}
Background: The prevalence of diabetes is increasing worldwide. Our study aimed to estimate the changing trends in the prevalence and incidence of diagnosed type 2 diabetes mellitus (T2DM) among Xiamen residents and the floating population using real-world data.

Method: We used real-world data from the System of Xiamen Citizens Health Information from 2014 to 2019 to estimate the changing trends in the prevalence and incidence of diagnosed T2DM. The System included the diagnosis of diabetes and the prescription of hypoglycemic drugs. Prevalent cases of T2DM were individuals who were diagnosed with T2DM and/or using hypoglycemic drugs. Incident cases were individuals with diagnosed T2DM and/or using hypoglycemic drugs in 2014 or 2019 who had not been diagnosed and/or did not use hypoglycemic drugs in the past.
\end{abstract}

Results: In 2014 and 2019, the prevalence of T2DM in Xiamen was 4.04 and 4.84\%, respectively. In 2014 and 2019, the incidence rate of T2DM in Xiamen was 14.1 per 1000 person-year and 15.0 per 1000 person-year, respectively. There was a significant increase in both the prevalence (Prevalence difference: $0.80,95 \% \mathrm{Cl} 0.76-0.83 \%, P<0.001$ ) and the incidence of T2DM (Incidence difference: $0.9,95 \% \mathrm{Cl} 0.7-1.1, P<0.001$ ). in Xiamen. The prevalence and incidence of T2DM in people aged 18-39 increased significantly $(P<0.001)$, while the prevalence and incidence of T2DM in people aged 40-69 reduced significantly $(P<0.001)$.

Conclusions: There was a significant increase in the prevalence and incidence of T2DM in Xiamen from 2014 to 2019 especially among those with younger age.

Keywords: Type 2 diabetes mellitus, Prevalence, Incidence, Xiamen

\footnotetext{
* Correspondence: lixuejun@xmu.edu.cn

${ }^{\dagger}$ Weiwei He and Qiushi Xu contributed equally to this work.

${ }^{2}$ Xiamen Diabetes Institute, The First Affiliated Hospital of Xiamen University, Xiamen 361003, China

${ }^{3}$ Fujian Provincial Key Laboratory of Translational Medicine for Diabetes, Xiamen 361003, China

Full list of author information is available at the end of the article
}

(c) The Author(s). 2021 Open Access This article is licensed under a Creative Commons Attribution 4.0 International License, which permits use, sharing, adaptation, distribution and reproduction in any medium or format, as long as you give appropriate credit to the original author(s) and the source, provide a link to the Creative Commons licence, and indicate if changes were made. The images or other third party material in this article are included in the article's Creative Commons licence, unless indicated otherwise in a credit line to the material. If material is not included in the article's Creative Commons licence and your intended use is not permitted by statutory regulation or exceeds the permitted use, you will need to obtain permission directly from the copyright holder. To view a copy of this licence, visit http://creativecommons.org/licenses/by/4.0/. The Creative Commons Public Domain Dedication waiver (http://creativecommons.org/publicdomain/zero/1.0/) applies to the data made available in this article, unless otherwise stated in a credit line to the data. 


\section{Background}

Diabetes is a chronic and progressive disease caused by genetic and environmental factors that can lead to a chronic damage, dysfunction, and even failure of multiple organs [1]. Owing to its high prevalence and high risk of disability, diabetes has become a serious health problem worldwide [2, 3]. With the rapid development of the economy, the improvement of people's living standards, and the change of lifestyle in China in the past three decades, diabetes has become a chronic disease that seriously endangers people's health [4]. Studies in recent years have shown that the global prevalence of diabetes is significantly increased and varies by age, geography, regional economic disparities, ethnicity, etc. [5].

Over the past 40 years, the prevalence of diabetes in China has increased from less than 1 to $12.8 \%$ in 2018 , and the prevalence of prediabetes is $35.2 \%$, making it the country with the largest number of diabetes cases in the world $[2,6]$. The total prevalence of diabetes in China from 2007 to 2008 was $9.7 \%$, among which the prevalence of diagnosed diabetes was $4.1 \%$ in males and 3.5\% in females [7]. The overall prevalence of diabetes in 2010 in China was $11.6 \%$, with the prevalence of diagnosed diabetes at $3.5 \%$ [5]. The overall prevalence of diabetes in 2013 in China was 10.9\%, of which the prevalence of diagnosed diabetes was $4.0 \%$ (3.9\% in males, $4.1 \%$ in females) [6].

Studies have revealed that the prevalence and the number of adults with diabetes have increased more in low- and middle-income countries than in middle- and high-income countries [8]. Rapid economic development and urbanization have resulted in an increasing burden of diabetes in many parts of the world [9]. As an important central city on the southeast coast of China, Xiamen's urbanization has reached up to $89.2 \%$. The data from the Xiamen Government Finance Bureau have shown that diabetes-related costs in Xiamen exceeded 43 million dollars in 2019, accounting for approximately $14.2 \%$ of the total annual cost of medical care. In terms of health expenditure, the global annual health expenditure on diabetes is estimated at 760 billion dollars. By 2030 , spending in this area is expected to reach 825 billion dollars [10]. The cost of diabetes care is statistically at least 3.2 times higher than the per capita medical expenditure and up to 9.4 times higher in the case of diabetes-related complications, so the impact on individuals and society at large if the development of diabetes is not controlled promptly is incalculable $[11,12]$. Therefore, exploring the prevalence and incidence of diabetes in Xiamen is of great significance to the management and China implemented healthcare reforms of diabetes in coastal areas of China. However, there are few data on the prevalence and incidence of diabetes in Xiamen.
In this study, we used real-world data from the System of Xiamen Citizen Health Information to estimate the changing trends in the prevalence and incidence of diagnosed type 2 diabetes mellitus (T2DM) among Xiamen residents and the floating population.

\section{Methods \\ Health system}

The data of this study were from the System of Xiamen Citizens Health Information, which is comprehensive information management and service platform jointly built by the Xiamen Municipal Health Bureau and China Mobile. All patients have a unique health insurance number and include information from all medical records of community hospitals, secondary and tertiary hospitals, and pharmacies, as well as diagnosis and medication information related to diabetes.

\section{Data collection}

In this study, the real-world data from the System of Xiamen Citizens Health Information included the diagnosis of diabetes and usage records of hypoglycemic drugs such as Biguanides, Sulfonylureas, Thiazolidinediones and DPP-4 inhibitors. Prevalent cases of T2DM were individuals who were diagnosed with T2DM and/ or used hypoglycemic drugs. To estimate the prevalence of T2DM in 2014 and 2019, we used data of System from 2014 and 2019, respectively. Incident cases were individuals with diagnosed T2DM and/or using hypoglycemic drugs in 2014 or 2019 who had not been diagnosed and/or no used one in the past. Incident cases were individuals with diagnosed T2DM and/or using hypoglycemic drugs in 2014 or 2019 who had not been diagnosed and/or did not use hypoglycemic drugs in the past.

\section{Statistical analysis}

We counted the number of people in the System who met the T2DM definition and used this as a numerator. Population denominator data for the years 2014 and 2019 were population estimates derived by the government based on the 2013 and 2018 censuses, respectively. When calculating the prevalence of T2DM in Xiamen's floating population in 2019, the denominator was based on the data of the floating population in Xiamen released by the government in 2018. In this study, all included T2DM patients were analyzed according to gender and age, the age groups were 18-29 years, 30-39 years, 40-49 years, 50-59 years, 60-69 years, and over 70 years. The information of each subgroup in 2019 was compared with that of 2014, and statistical analysis was carried out using SPSS18.0 and $x^{2}$ test, with $P<0.05$ indicating that the difference was statistically significant. 
Table 1 Prevalence rates of type 2 diabetes in 2014 and 2019

\begin{tabular}{|c|c|c|c|c|c|c|c|c|}
\hline & \multicolumn{3}{|c|}{2014 population } & \multicolumn{3}{|c|}{2019 population } & \multirow[b]{2}{*}{$\begin{array}{l}\text { Prevalence difference } \\
(95 \% \mathrm{Cl})\end{array}$} & \multirow[b]{2}{*}{$P$ value } \\
\hline & $\begin{array}{l}\text { No. of } \\
\text { diabetes }\end{array}$ & General & $\begin{array}{l}\text { Prevalence (\%) } \\
(95 \% \mathrm{Cl})\end{array}$ & $\begin{array}{l}\text { No. of } \\
\text { diabetes }\end{array}$ & General & $\begin{array}{l}\text { Prevalence (\%) } \\
(95 \% \mathrm{Cl})\end{array}$ & & \\
\hline Total & 118,468 & $\begin{array}{l}2,932 \\
637\end{array}$ & $4.04(4.02-4.06)$ & 140,535 & $\begin{array}{l}2,905 \\
138\end{array}$ & $4.84(4.81-4.86)$ & $0.80(0.76-0.83)$ & $<0.001$ \\
\hline \multicolumn{9}{|l|}{ Sex } \\
\hline Females & 68,641 & $\begin{array}{l}1,455 \\
557\end{array}$ & $4.72(4.68-4.75)$ & 78,553 & $\begin{array}{l}1,423 \\
444\end{array}$ & $5.52(5.48-5.56)$ & $0.80(0.75-0.85)$ & $<0.001$ \\
\hline Males & 49,787 & $\begin{array}{l}1,477 \\
080\end{array}$ & 3.37 (3.34-3.40) & 61,982 & $\begin{array}{l}1,481 \\
694\end{array}$ & $4.18(4.15-4.22)$ & $0.81(0.77-0.86)$ & $<0.001$ \\
\hline \multicolumn{9}{|l|}{ Age, Years } \\
\hline $18-29$ & 5143 & 857,876 & $0.60(0.58-0.62)$ & 4141 & 530,836 & $0.78(0.76-0.80)$ & $0.18(0.15-0.21)$ & $<0.001$ \\
\hline $30-39$ & 14,378 & 775,476 & $1.85(1.82-1.88)$ & 17,594 & 836,915 & $2.10(2.07-2.13)$ & $0.25(0.21-0.29)$ & $<0.001$ \\
\hline $40-49$ & 19,945 & 620,726 & $3.21(3.17-3.26)$ & 18,513 & 627,754 & $2.95(2.91-2.99)$ & $-0.26(-0.33 \sim-0.20)$ & $<0.001$ \\
\hline $50-59$ & 29,073 & 343,264 & $8.47(8.38-8.56)$ & 29,840 & 447,403 & $6.67(6.60-6.74)$ & $-1.80(-1.92 \sim-1.68)$ & $<0.001$ \\
\hline $60-69$ & 26,348 & 194,072 & $13.58(13.42-13.73)$ & 34,804 & 270,315 & $12.88(12.75-13.00)$ & $-0.70(-0.90 \sim-0.50)$ & $<0.001$ \\
\hline$\geq 70$ & 23,581 & 134,473 & 17.54 (17.33-17.74) & 35,643 & 191,915 & 18.57 (18.40-18.75) & $1.04(0.77 \sim 1.30)$ & $<0.001$ \\
\hline
\end{tabular}

(95\%Cl, 95\% confidence interval)

\section{Results}

\section{Prevalence of T2DM in Xiamen}

In 2014, the resident population of Xiamen was 2,932, 637 and the number of T2DM patients was 118,468, with a prevalence of $4.04 \%$. The prevalence of T2DM increased with age, and it grows rapidly after the age of 40 years old. The number of patients aged 50-59 years old was the largest, with a prevalence of $8.47 \%$ (95\% CI 8.38 8.56). The prevalence was as high as $17.54 \%$ (95\%CI 17.33-17.74) in people over 70 years old. The prevalence of T2DM was $0.60 \%(95 \% \mathrm{CI}, 0.58-0.62)$ among $18-29$ years old (Table 1; Fig. 1).
In 2019, the resident population of Xiamen was 2,905, 138 , with a total of 140,535 T2DM patients, with a prevalence of $4.84 \%$ (95\%CI 4.81-4.86). The prevalence of T2DM among women was also higher than men, with $5.52 \%$ (95\%CI 5.48-5.56) and 4.18\% (95\%CI 4.15-4.22), respectively. Among the patients, 35,643 patients over the age of 70 years had the most cases of T2DM, with a prevalence of $18.57 \%$ (95\%CI $18.40-18.75)$. The prevalence of T2DM was $0.78 \%$ (95\%CI $0.76-0.80$ ) among the age of 18-29 years old. The prevalence of T2DM increased with age in both men and women and increased sharply after the age of 50 years old.

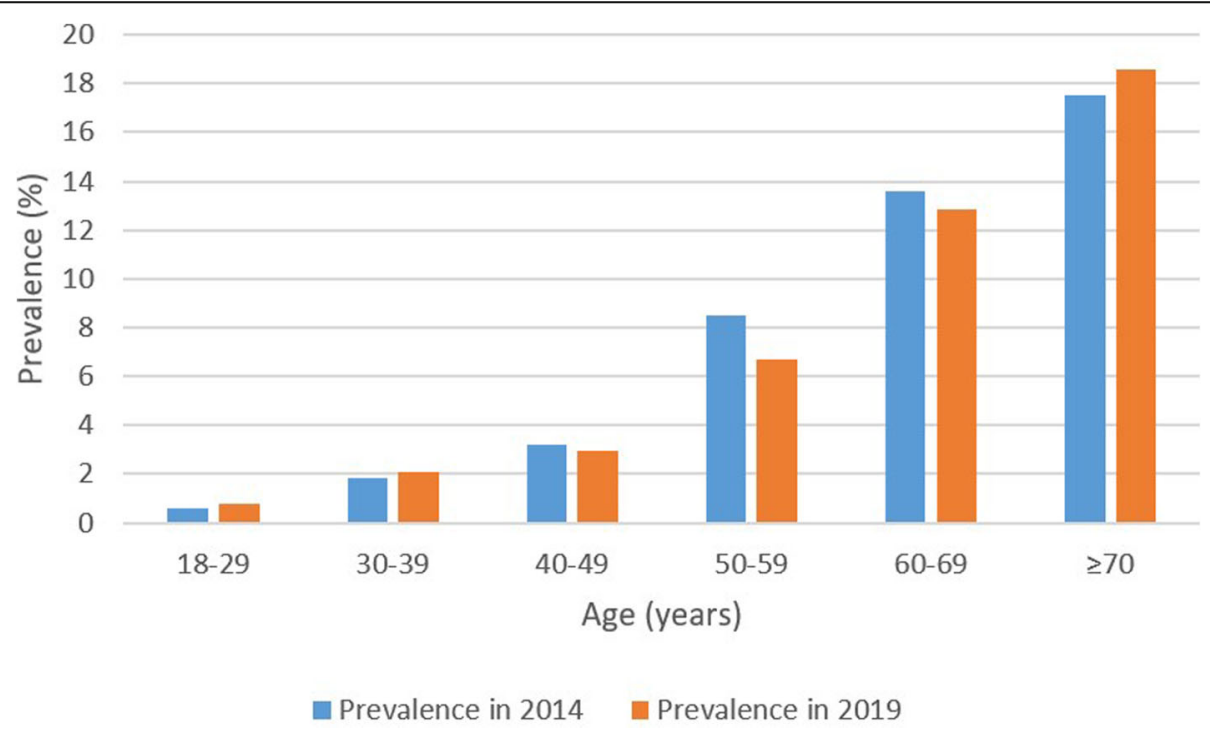

Fig. 1 Prevalence of type 2 diabetes mellitus among populations with different ages in 2014 and 2019 
The change in the prevalence of T2DM in Xiamen

There was a significant increase in the prevalence of T2DM from 2014 to 2019, and the difference in the increase was $0.80 \%$ ( $95 \% \mathrm{CI}, 0.76-0.83 \%)$. The increase from 2014 to 2019 was $0.18 \%(95 \% \mathrm{CI}, 0.15-0.21 \%)$ in the age of $18-29$ years old, $0.25 \%$ (95\%CI, $0.21-0.29 \%$ ) in the age of $30-39$ years old, and $1.04 \%(0.77-1.30 \%)$ in the age of over 70 years old. There was a reduction from 2014 to 2019 among the age of 40-69 years old. The reduction was $0.26 \%(95 \% \mathrm{CI}, 0.20-0.33 \%)$ in the age of $40-49$ years old, $1.80 \%(95 \% \mathrm{CI}, 1.68-1.92 \%)$ in the age of $50-59$ years old, and $0.70(95 \% \mathrm{CI}, 0.50-0.90 \%)$ in the age of $60-69$ years old (Table 1; Fig. 1).

\section{Incidence rate of T2DM in Xiamen}

In 2014, the incidence rate of T2DM in Xiamen was 14.1 per 1000 (95\%CI, 13.9-14.2), and the incidence rate of females was higher than that of men, which was 15.9 per 1000 (95\%CI, 15.7-16.1) and 11.6 per 1000 (95\%CI, 11.4-11.8), respectively. The number of newly diagnosed T2DM patients aged 50-59 years old was the largest, and the incidence rate was 30.4 per 1000 (95\%CI, 29.831.0). The highest incidence rate of new cases was 63.3 per $1000(95 \% \mathrm{CI}, 61.9-64.7)$ occurred at the age of over 70 years old. The incidence rate of T2DM was 2.6 per $1000(95 \% \mathrm{CI}, 2.5-2.7)$ at the age of $18-29$ years old (Table 2; Fig. 2).

In 2019, the incidence rate of T2DM was 15.0 per 1000 (95\% CI, 14.8-15.1), and the incidence rate of females was still higher than that of males, which was 16.7 per 1000 (95\%CI, 16.5-16.9) and 13.4 per 1000 (95\%CI, 13.2-13.6), respectively. The number of newly diagnosed T2DM patients aged $60-69$ years old was 9732 , with an incidence rate of 40.8 per 1000 (95\%CI, 40.0-41.6). The incidence rate of newly diagnosed T2DM patients over the age of 70 years old was the highest in the same year, as high as 56.3 per 1000 (95\%CI, 55.2-57.5). The incidence rate of T2DM increased with age in both men and women and increased sharply after the age of 50 years old.

\section{The change in the incidence rate of T2DM in Xiamen}

There was an increase in the incidence of T2DM from 2014 to 2019 , and the difference in the incidence rate was $0.9 \%(95 \% \mathrm{CI}, 0.7-1.1)$. The increase from 2014 to 2019 was $0.4 \%(95 \% \mathrm{CI}, 0.2-0.6)$ in the age of $18-29$ years old. There was a reduction from 2014 to 2019 over the age of 40 years old. The reduction was $0.6 \%(95 \% \mathrm{CI}$, $0.2 \sim 1.0)$ in the age of $40-49$ years old, $8.5 \%$ (95\% CI, 7.8 9.3) in the age of $50-59$ years old, $7.4 \%$ (95\%CI, $6.1 \sim$ 8.7 ) in the age of $60-69$ years old, and $7.0 \%$ (95\%CI, 5.2 8.8) over the age of 70 years old (Table 2; Fig. 2).

The prevalence of T2DM among the floating population In 2019, there were 840,443 floating population in Xiamen, of which 7933 were diagnosed with T2DM, with a prevalence of $0.94 \%$ (95\% CI 0.92-0.97). Among them, the age of 30-39 years old was the largest population with T2DM, and the prevalence was $1.13 \%$ (95\% CI 1.09-1.17). The prevalence of T2DM over 70 years old was the highest, as high as $2.64 \%(95 \% \mathrm{CI} 2.26-3.01)$ (Table 3).

\section{Discussion}

In this study, we found that there was a significant increase in the prevalence and incidence rate of T2DM in

Table 2 Incidence rates of type 2 diabetes in 2014 and 2019

\begin{tabular}{|c|c|c|c|c|c|c|c|c|}
\hline & \multicolumn{3}{|c|}{2014 population } & \multicolumn{3}{|c|}{2019 population } & \multirow[b]{2}{*}{$\begin{array}{l}\text { Rate difference } \\
(95 \% \mathrm{Cl})\end{array}$} & \multirow[b]{2}{*}{$P$ value } \\
\hline & $\begin{array}{l}\text { No. of } \\
\text { diabetes }\end{array}$ & $\begin{array}{l}\text { Total } \\
\text { person- } \\
\text { year }\end{array}$ & $\begin{array}{l}\text { Incidence rate, per } 1000 \\
\text { person-year }\end{array}$ & $\begin{array}{l}\text { No. of } \\
\text { diabetes }\end{array}$ & $\begin{array}{l}\text { Total } \\
\text { person- } \\
\text { year }\end{array}$ & $\begin{array}{l}\text { Incidence rate, per } 1000 \\
\text { person-year }\end{array}$ & & \\
\hline Total & 39,947 & $2,843,850$ & $14.1(13.9-14.2)$ & 41,663 & $2,780,967$ & $15.0(14.8-15.1)$ & $0.9(0.7-1.1)$ & $<0.001$ \\
\hline \multicolumn{9}{|l|}{ Sex } \\
\hline Females & 22,274 & $1,404,400$ & $15.9(15.7-16.1)$ & 22,585 & $1,355,475$ & $16.7(16.5-16.9)$ & $0.8(0.5-1.1)$ & $<0.001$ \\
\hline Males & 16,673 & $1,439,450$ & $11.6(11.4-11.8)$ & 19,078 & $1,425,492$ & $13.4(13.2-13.6)$ & $1.8(1.5-2.1)$ & $<0.001$ \\
\hline \multicolumn{9}{|l|}{ Age, Years } \\
\hline $18-29$ & 2253 & 854,868 & $2.6(2.5-2.7)$ & 1617 & 528,056 & $3.1(2.9-3.2)$ & $0.4(0.2-0.6)$ & $<0.001$ \\
\hline $30-39$ & 4932 & 765,511 & $6.4(6.3-6.6)$ & 5455 & 823,436 & $6.6(6.5-6.8)$ & $0.2(-0.1 \sim 0.4)$ & 0.155 \\
\hline $40-49$ & 6980 & 606,211 & $11.5(11.3-11.8)$ & 6664 & 610,178 & $10.9(10.7-11.2)$ & $-0.6(-1.0 \sim-0.2)$ & 0.002 \\
\hline $50-59$ & 9758 & 321,105 & $30.4(29.8-31.0)$ & 9210 & 421,281 & $21.9(21.4-22.3)$ & $\begin{array}{l}-8.5(-9.3 \sim \\
-7.8)\end{array}$ & $<0.001$ \\
\hline $60-69$ & 8698 & 180,487 & $48.2(47.2-49.2)$ & 9732 & 238,499 & $40.8(40.0-41.6)$ & $-7.4(-8.7 \sim-6.1)$ & $<0.001$ \\
\hline$\geq 70$ & 7326 & 115,678 & $63.3(61.9-64.7)$ & 8985 & 159,517 & $56.3(55.2-57.5)$ & $\begin{array}{l}-7.0(-8.8 \sim \\
-5.2)\end{array}$ & $<0.001$ \\
\hline
\end{tabular}




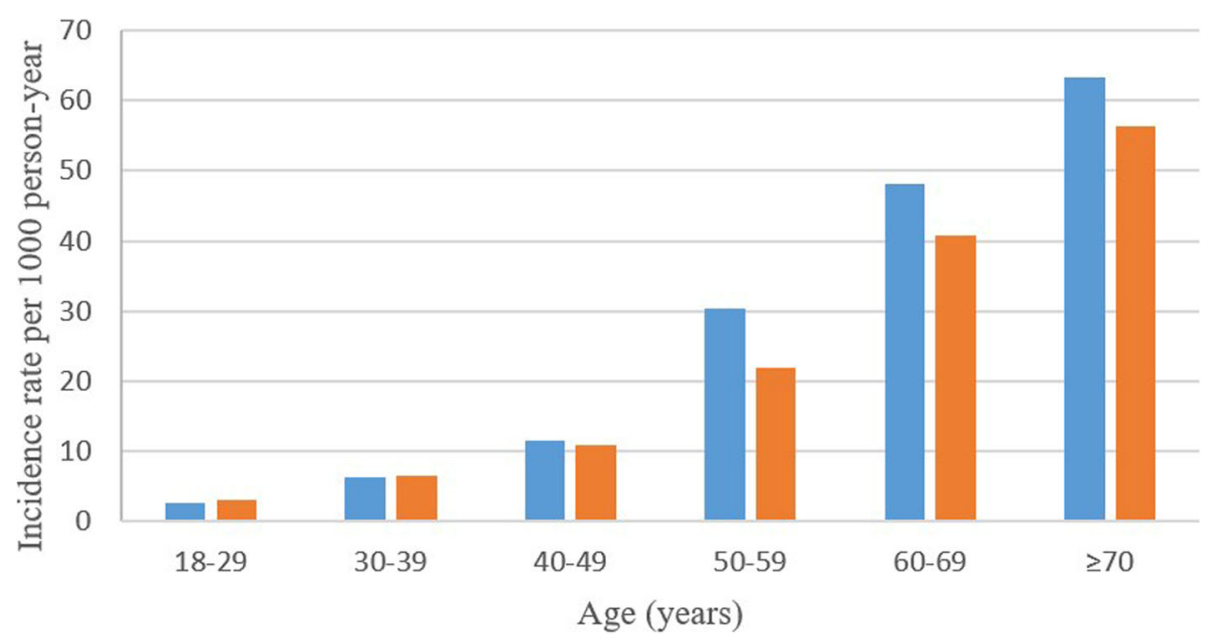

- Incidence rate in 2014 Incidence rate in 2019

Fig. 2 Incidence rate of type 2 diabetes mellitus among populations with different ages in 2014 and 2019

Xiamen from 2014 to 2019 . The prevalence and incidence rate of T2DM in people aged 18-29 and 30-39 years old increased significantly from 2014 to 2019, while the prevalence and incidence rate of T2DM in people aged 40-69 years old reduced from 2014 to 2019, indicating that the T2DM patients in Xiamen showed a trend of younger age. The result of our study was consistent with the concept that diabetes tends to be greater among the young in Asia [13]. The results mentioned above showed that one in five adult patients was diagnosed with T2DM before the age of 40 years old and those younger patients with T2DM had poor awareness of disease management, suggesting that more young people will suffer from T2DM in the future [13]. More focused efforts are needed to improve risk factor control strategies for people under the age of 40 years, including

Table 3 Prevalence of type 2 diabetes in the floating population in 2019

\begin{tabular}{cllll}
\hline & No. of diabetes & Population & Estimate (\%) & $\mathbf{9 5 \% ~ C l}$ \\
\hline $\begin{array}{c}\text { Total } \\
\text { Sex }\end{array}$ & 7933 & 840,443 & 0.94 & $0.92-0.97$ \\
Females & 5203 & 367,754 & 1.42 & $1.38-1.45$ \\
Males & 2730 & 472,689 & 0.58 & $0.56-0.60$ \\
Age, years & & & & \\
$18-29$ & 1388 & 307,385 & 0.45 & $0.43-0.48$ \\
$30-39$ & 3010 & 265,476 & 1.13 & $1.09-1.17$ \\
$40-49$ & 1589 & 143,763 & 1.11 & $1.05-1.16$ \\
$50-59$ & 1229 & 86,816 & 1.42 & $1.34-1.49$ \\
$60-69$ & 532 & 30,017 & 1.77 & $1.62-1.92$ \\
$\geq 70$ & 185 & 7016 & 2.64 & $2.26-3.01$ \\
\hline
\end{tabular}

prevention measures for obesity and inadequate lifestyles, and younger screening for diabetes for those persons at risk. Compared with the prevalence of T2DM in 2014, the rapid increase in prevalence in 2019 is closely related to the economic development of Xiamen in recent years, the improvement of people's living standards, the acceleration of urbanization, and the aging population, etc. With the development of the economy, people's lifestyles such as dietary structure have undergone major changes, the proportion of cereal intake has decreased, the proportion of meat and fat has increased, fat intake has increased, physical exercise has decreased, all of these can promote the occurrence and development of overweight, obesity, and diabetes [14-16]. This shows that the situation of prevention and treatment of diabetes in Xiamen needs to be taken seriously.

The results of our study found that the prevalence of diagnosed T2DM in Xiamen was $4.84 \%$ in 2019. The prevalence among men and women was 4.18 and $5.52 \%$, respectively, which were higher than the prevalence of diagnosed diabetes in 2007, 2010, and 2013 in China. A large national study in mainland China published recently showed that $11.2 \%$ of adults (according to WHO standards) or $12.8 \%$ of adults (according to ADA standards) had diabetes in 2018, as a result, China was estimated to be 129.8 million persons with diabetes (70.4 million males and 59.4 million females), of which the prevalence of diagnosed diabetes was $6.0 \%$ (6.4\% in men, $5.6 \%$ in women) [17]. The overall prevalence of diabetes is higher in urban than rural areas, but the gap between urban and rural areas is narrowing year by year. The survey concluded that the prevalence of diabetes among adults living in China increased slightly from 2007 to 
2017 and that diabetes is an important public health problem in China that requires ongoing surveillance and effective control to reduce its burden. The prevalence of diabetes continues to increase globally, and the trend in diabetes prevalence in China is consistent with that worldwide. Compared to Europe, Chinese patients with T2DM show a younger trend and a lower BMI [18]. .According to the study, the prevalence of diagnosed diabetes in urban and southern China was 7.1 and 5.8\% respectively, both higher than the prevalence of T2DM in Xiamen in our study. It has been reported that the incidence of diagnosed T2DM in Beijing decreased from $24.3(95 \% \mathrm{CI}, 24.2,24.4)$ per 1000 person-years in 2008 to $11.5(95 \% \mathrm{CI}, 11.5,11.6)$ per 1000 person-years in 2017, while our study showed that the incidence of diagnosed T2DM increased significantly in 2019 compared with 2014. Consistent with their findings was a higher prevalence and incidence in women than in men [19]. The lower prevalence and incidence rate of T2DM in Xiamen compared to the studies mentioned above may be attributed to many factors. There is considerable evidence that Western diets characterized by meat are significantly associated with T2DM, while Mediterranean diets characterized by plants are associated with a low risk of diabetes [20, 21]. A meta-analysis has concluded that intake of red meat and processed meat is positively associated with the risk of T2DM, while intake of aquatic products has no significant correlation with the risk of T2DM [22]. Our study showed that the prevalence of diagnosed T2DM in Xiamen was lower than the prevalence of diagnosed diabetes in China in 2018 (4.84\% vs 6.0\%), which may be related to the fact that Xiamen is located in the coastal area of China, where the seafood is abundant and diverse, and the per capita daily intake of aquatic products of Xiamen residents is higher than the average level of all over the world.

The prevalence of diabetes among the floating population is lower than that of the general population, but considering the growth rate of the floating population and the poor disease management awareness among the floating population, the potential threat posed by diabetes among this group cannot be ignored [23-26]. In 2017, a study calculated that the prevalence of diabetes among the floating population in China was 5.1\% (95\%CI 4.9-5.3), and the prevalence was higher among women than men [25]. Xiamen is a developed coastal economic region with a large migrant population, but there are few reports on the prevalence of diabetes among the floating population. This study explored this issue for the first time and found that in 2019, the number floating population in Xiamen was 840,443, and the prevalence of $\mathrm{T} 2 \mathrm{DM}$ was $0.94 \%(1.42 \%$ in women, $0.58 \%$ in men). The number of aged 18-29 years old persons was the most floating population, with a prevalence of $0.45 \%$. Those persons over 70 years old have the highest T2DM prevalence, which was $2.64 \%$. It can be seen from the above data that the prevalence of diabetes among the floating population in Xiamen is far lower than the national average level, which may be attributed to the following reasons: 1) Most of the floating population in Xiamen are working people with good physical fitness and great exercise intensity, and there are fewer obese or overweight people, thus reducing the risk of diabetes. 2) Most of the floating population who come to Xiamen does not have medical insurance in Xiamen, so it may not be possible to record diagnosed diabetes cases into the System of Xiamen citizen health information. Overall, the government and the hospital should offer T2DM knowledge lectures or online classes for the floating population in Xiamen, to improve their selfmanagement awareness of T2DM, and effectively control the epidemic trend of T2DM in the floating population.

The strength of our study included a large sample of a population-based longitudinal study to direct comparison of T2DM prevalence and incidence from 2014 to 2019 in the population in Xiamen. The prevalence and incidence rate of T2DM in this study were evaluated based on real and reliable data. There were also several limitations to our study. Firstly, the study did not analyze patients with undiagnosed diabetes who had T2DM but did not receive standard diabetes care or hypoglycemic medications. However, Xiamen is a city with universal health insurance coverage and has relatively good medical coverage compared to other cities in China. Therefore, the current study design can provide a relatively accurate assessment of the prevalence or epidemiology of diabetes in Xiamen. Secondly, the types of hypoglycemic drugs used by patients with diabetes in Xiamen are diverse, and many patients have changed their hypoglycemic drugs frequently, which make it difficult to determine the types of hypoglycemic drugs they commonly use and the changes in the medication use over time. The use of hypoglycemic medications among persons with diabetes in Xiamen and the changes in medication use over time need to be explored in future researches. Thirdly, the prevalence and incidence of T2DM among women in Xiamen were higher than that among men in Xiamen. The clinical visit rates among women in Xiamen are higher than that among men, which is a possible reason for the higher prevalence and incidence of T2DM among women in Xiamen. Finally, we only analyzed T2DM and had no information on other types of diabetes including type 1 diabetes. It is true that some subjects are poorly accessible to medical services, and this issue is indeed a limitation of our study design that may affect the accuracy of the results or data of this study. 


\section{Conclusion}

In conclusion, our study used real data from the System of Xiamen Citizen Health Information to estimate trends in the prevalence and incidence of T2DM in Xiamen. We found that the prevalence and incidence rate of T2DM in Xiamen showed a significant increase from 2014 to 2019, and it was more severe among younger people. Through the System of Xiamen Citizens Health Information, the purpose of real-time monitoring trends in prevalence and incidence of T2DM can be achieved, thereby providing a basis for health policies and health service plans.

\section{Abbreviations}

T2DM: Type 2 diabetes mellitus; Cl: Confidence interval

\section{Acknowledgments}

We are grateful to all the individuals who participated in this study.

\section{Authors' contributions}

All of the authors contributed to the design of the study. $X J L$ designed the study. WH and QS X wrote the manuscript. QS X collected, analyzed the data with $W H, L H, L S Y$ and TW. GH Y and XL S gave much advice and directions in both study design and preparing of the manuscript. All the authors have read and approved the final submitted version. Weiwei He and Qiushi Xu these authors are contributed to the article equally.

\section{Funding}

This work was supported by the National Natural Science Foundation of China (No. 81870606). The funding body plays no role in the design of the study and collection, analysis, and interpretation of data and in writing the manuscript.

\section{Availability of data and materials}

The datasets generated or analyzed during the current study are not publicly available due to data sharing policies but are available from the corresponding author on reasonable request.

\section{Declarations}

\section{Consent to publication}

Not applicable.

\section{Ethics approval and consent to participate}

The study was approved by both the Ethics Committee at the First Affiliated Hospital of Xiamen University and Xiamen Municipal Health Commission. The System of Xiamen citizen health information is a collaborative platform for medical institutions authorized by the Xiamen Municipal Health Commission, and users can access the raw data with the approval of the Xiamen Municipal Health Commission.

\section{Competing interests}

The authors declare that they have no competing interests.

\section{Author details}

${ }^{1}$ School of Medicine, Xiamen University, Xiamen 361003, China. ${ }^{2}$ Xiamen Diabetes Institute, The First Affiliated Hospital of Xiamen University, Xiamen 361003, China. ${ }^{3}$ Fujian Provincial Key Laboratory of Translational Medicine for Diabetes, Xiamen 361003, China. ${ }^{4}$ Xiamen Health and Medical Big Data Center, Xiamen, China. ${ }^{5}$ Fujian Medical University, Fuzhou, Fujian, China. ${ }^{6}$ Department of Endocrinology and Diabetes, The First Affiliated Hospital of Xiamen University, No.55 Zhenhai Road, Xiamen 361003, China. ${ }^{7}$ Xiamen Municipal Health Commission, Xiamen, China.
Received: 30 September 2020 Accepted: 20 April 2021

Published online: 01 May 2021

\section{References}

1. Cho NH, Shaw JE, Karuranga S, Huang Y, da Rocha Fernandes JD, Ohlrogge AW, et al. IDF diabetes atlas: global estimates of diabetes prevalence for 2017 and projections for 2045. Diabetes Res Clin Pract. 2018;138:271-81.

2. Fonseca VA. Defining and characterizing the progression of type 2 diabetes. Diabetes Care. 2009;32(Suppl 2):S151-6.

3. Disease GBD, Injury I, Prevalence C. Global, regional, and national incidence, prevalence, and years lived with disability for 328 diseases and injuries for 195 countries, 1990-2016: a systematic analysis for the global burden of Disease study 2016. Lancet. 2017;390(10100):1211-59.

4. Yang G, Kong L, Zhao W, Wan X, Zhai Y, Chen LC, et al. Emergence of chronic non-communicable diseases in China. Lancet. 2008;372(9650):1697705.

5. Xu Y, Wang L, He J, Bi Y, Li M, Wang T, et al. Prevalence and control of diabetes in Chinese adults. Jama. 2013;310(9):948-59.

6. Wang L, Gao P, Zhang M, Huang Z, Zhang D, Deng Q, et al. Prevalence and ethnic pattern of diabetes and prediabetes in China in 2013. Jama. 2017; 317(24):2515-23.

7. Shi Z. Prevalence of diabetes among men and women in China. N Engl J Med. 2010;362(25):2425 author reply 2426

8. Onyango EM, Onyango BM. The rise of noncommunicable diseases in Kenya: an examination of the time trends and contribution of the changes in diet and physical inactivity. J Epidemiol Glob Health. 2018;8(1-2):1-7.

9. Chow CK, Ramasundarahettige C, Hu W, AlHabib KF, Avezum A Jr, Cheng X, et al. Availability and affordability of essential medicines for diabetes across high-income, middle-income, and low-income countries: a prospective epidemiological study. Lancet Diab Endocrinol. 2018;6(10):798-808.

10. International Diabetes Federation. IDF Diabetes Atlas. 9th ed. Brussels; 2019. Available at: http://www.diabetesatlas.org

11. Al-Maskari F, El-Sadig M, Nagelkerke N. Assessment of the direct medical costs of diabetes mellitus and its complications in the United Arab Emirates. BMC Public Health. 2010:10:679.

12. Bommer C, Sagalova V, Heesemann E, Manne-Goehler J, Atun R, Barnighausen T, et al. Global economic burden of diabetes in adults: projections from 2015 to 2030. Diabetes Care. 2018;41(5):963-70.

13. Zhang $Y$, Ning G. Diabetes: young-onset type 2 diabetes mellitus-a challenge for Asia. Nat Rev Endocrinol. 2014;10(12):703-4.

14. Wu Y. Overweight and obesity in China. Bmj. 2006:333(7564):362-3.

15. Lone S, Lone K, Khan S, Pampori RA. Assessment of metabolic syndrome in Kashmiri population with type 2 diabetes employing the standard criteria's given by WHO, NCEPATP III and IDF. J Epidemiol Glob Health. 2017;7(4): 235-9.

16. Zhang N, Du SM, Ma GS. Current lifestyle factors that increase risk of T2DM in China. Eur J Clin Nutr. 2017:71(7):832-8

17. Li Y, Teng D, Shi $X$, Qin G, Qin Y, Quan H, et al. Prevalence of diabetes recorded in mainland China using 2018 diagnostic criteria from the American Diabetes Association: national cross sectional study. Bmj. 2020; 369:m997.

18. Hu C, Jia W. Diabetes in China: epidemiology and genetic risk factors and their clinical utility in personalized medication. Diabetes. 2018;67(1):3-11.

19. Wang Z, Wu Y, Wu J, Wang M, Wang X, Wang J, et al. Trends in prevalence and incidence of type 2 diabetes among adults in Beijing, China, from 2008 to 2017. Diabet Med. 2020;1:e14487.

20. Jannasch F, Kroger J, Schulze MB. Dietary patterns and type 2 diabetes: a systematic literature review and meta-analysis of prospective studies. J Nutr. 2017:147(6):1174-82.

21. Schwingshackl L, Missbach B, Konig J, Hoffmann G. Adherence to a Mediterranean diet and risk of diabetes: a systematic review and metaanalysis. Public Health Nutr. 2015;18(7):1292-9.

22. Schwingshackl L, Hoffmann G, Lampousi AM, Knuppel S, lqbal K, Schwedhelm C, et al. Food groups and risk of type 2 diabetes mellitus: a systematic review and meta-analysis of prospective studies. Eur J Epidemiol. 2017:32(5):363-75

23. Bi $Y$, Wang $L, X u Y$, Jiang $Y, H e J$, Zhang $M$, et al. Diabetes-related metabolic risk factors in internal migrant workers in China: a national surveillance study. Lancet Diabetes Endocrinol. 2016;4(2):125-35. 
24. Yao X, Wang P, Qian Y, Liu A. A cross-sectional study on diabetes among the migrating population in Inner Mongolia. Zhonghua liu xing bing xue za zhi. 2014;35(8):896-900

25. Han K, Yao J, Yin X, Zhao M, Sun Q. Review on the prevalence of diabetes and risk factors and situation of disease management in floating population in China. Glob Health Res Policy. 2017;2:33.

26. Shao Jl, Zhu ZS. Study of population movements and the changes in the pattern of urbanization. Res Econ Manage. 2013;12:75-83.

\section{Publisher's Note}

Springer Nature remains neutral with regard to jurisdictional claims in published maps and institutional affiliations.

Ready to submit your research? Choose BMC and benefit from:

- fast, convenient online submission

- thorough peer review by experienced researchers in your field

- rapid publication on acceptance

- support for research data, including large and complex data types

- gold Open Access which fosters wider collaboration and increased citations

- maximum visibility for your research: over $100 \mathrm{M}$ website views per year

At $B M C$, research is always in progress.

Learn more biomedcentral.com/submissions 